\title{
Pathobiological Relationship of Excessive Dietary Intake of Choline/L-Carnitine: A TMAO Precursor-Associated Aggravation in Heart Failure in Sarcopenic Patients
}

\author{
May Nasser Bin-Jumah 1,2 ${ }^{(D}$, Sadaf Jamal Gilani ${ }^{3}$, Salman Hosawi ${ }^{4}$ (D) Fahad A. Al-Abbasi ${ }^{4}$, Mustafa Zeyadi ${ }^{4}$, \\ Syed Sarim Imam ${ }^{5}\left(\mathbb{D}\right.$, Sultan Alshehri ${ }^{5} \mathbb{D}$, Mohammed M Ghoneim ${ }^{6}\left(\mathbb{D}\right.$, Muhammad Shahid Nadeem ${ }^{4}$ and \\ Imran Kazmi ${ }^{4, *}$ (D)
}

check for updates

Citation: Bin-Jumah, M.N.; Gilani, S.J.; Hosawi, S.; Al-Abbasi, F.A.; Zeyadi, M.; Imam, S.S.; Alshehri, S.; Ghoneim, M.M.; Nadeem, M.S.; Kazmi, I. Pathobiological Relationship of Excessive Dietary Intake of Choline/L-Carnitine: A TMAO Precursor-Associated Aggravation in Heart Failure in Sarcopenic Patients. Nutrients 2021, 13, 3453. https://doi.org/10.3390/ nu13103453

Academic Editor: Hayato Tada

Received: 30 July 2021

Accepted: 27 September 2021

Published: 29 September 2021

Publisher's Note: MDPI stays neutral with regard to jurisdictional claims in published maps and institutional affiliations.

Copyright: (C) 2021 by the authors Licensee MDPI, Basel, Switzerland. This article is an open access article distributed under the terms and conditions of the Creative Commons Attribution (CC BY) license (https:// creativecommons.org/licenses/by/ $4.0 /)$.
1 Biology Department, College of Science, Princess Nourah Bint Abdulrahman University, Riyadh 11671, Saudi Arabia; mnbinjumah@pnu.edu.sa

2 Environment and Biomaterial Unit, Health Sciences Research Center, Princess Nourah bint Abdulrahman University, Riyadh 11671, Saudi Arabia

3 Department of Basic Health Sciences, Preparatory Year, Princess Nourah Bint Abdulrahman University, Riyadh 11671, Saudi Arabia; SJGlani@pnu.edu.sa

4 Department of Biochemistry, Faculty of Science, King Abdulaziz University, Jeddah 21589, Saudi Arabia; shosawi@kau.edu.sa (S.H.); fabbasi@kau.edu.sa (F.A.A.-A.); mzyadi@kau.edu.sa (M.Z.); mhalim@kau.edu.sa (M.S.N.)

5 Department of Pharmaceutics, College of Pharmacy, King Saud University, Riyadh 11451, Saudi Arabia; simam@ksu.edu.sa (S.S.I.); salshehri1@ksu.edu.sa (S.A.)

6 Department of Pharmacy Practice, College of Pharmacy, AlMaarefa University, Ad Diriyah 13713, Saudi Arabia; mghoneim@mcst.edu.sa

* Correspondence: ikazmi@kau.edu.sa

Abstract: The microecological environment of the gastrointestinal tract is altered if there is an imbalance between the gut microbiota phylases, resulting in a variety of diseases. Moreover, progressive age not only slows down physical activity but also reduces the fat metabolism pathway, which may lead to a reduction in the variety of bacterial strains and bacteroidetes' abundance, promoting firmicutes and proteobacteria growth. As a result, dysbiosis reduces physiological adaptability, boosts inflammatory markers, generates ROS, and induces the destruction of free radical macromolecules, leading to sarcopenia in older patients. Research conducted at various levels indicates that the microbiota of the gut is involved in pathogenesis and can be considered as the causative agent of several cardiovascular diseases. Local and systematic inflammatory reactions are caused in patients with heart failure, as ischemia and edema are caused by splanchnic hypoperfusion and enable both bacterial metabolites and bacteria translocation to enter from an intestinal barrier, which is already weakened, to the blood circulation. Multiple diseases, such as HF, include healthy microbe-derived metabolites. These key findings demonstrate that the gut microbiota modulates the host's metabolism, either specifically or indirectly, by generating multiple metabolites. Currently, the real procedures that are an analogy to the symptoms in cardiac pathologies, such as cardiac mass dysfunctions and modifications, are investigated at a minimum level in older patients. Thus, the purpose of this review is to summarize the existing knowledge about a particular diet, including trimethylamine, which usually seems to be effective for the improvement of cardiac and skeletal muscle, such as choline and L-carnitine, which may aggravate the HF process in sarcopenic patients.

Keywords: sarcopenia; heart failure; trimethylamine-N-oxide; inflammatory mediators; choline; L-carnitine

\section{Introduction}

The human intestine microbiota is primarily comprised of four phyla: proteobacteria, firmicutes, actinobacteria, and bacteroidetes [1]. An imbalance between the gut microbiota 
phylases alters the microecological environment of a gastrointestinal tract, resulting in numerous diseases. The gut microbiota has many important functions in sustaining host fitness, including host feeding and energy harvesting, intestinal homeostasis, drug absorption and toxicity, immune system responsiveness, and pathogen defense. They can also produce microbial products such as bile acids, trimethylamine-N-oxide (TMAO), lipopolysaccharides (LPS), vitamin B complexes, vitamin K, uremic toxins, nitric oxide, fatty acids in the short-chain (SCFA), gut neurotransmitters, and hormones, which can modify host metabolism and influence both the health and diseases working in the body [2] Moreover, progressive age not only slows down physical activity but also reduces the fat metabolism pathway, which may lead to a reduction in the variety of bacterial strains and bacteroidetes' abundance, promoting firmicutes and proteobacteria growth. As a result, dysbiosis reduces physiological adaptability, boosts inflammatory markers, creates ROS, and induces the destruction of free radical macromolecules, leading to sarcopenia in older patients $[3,4]$. As aging became a global epidemic, decreased muscle mass in octogenarians (or older persons) impaired 5-13\% of elderly people between 60 and 70 years old and has an incidence rate of up to 50\% [5]. In a multi-continent sample, sarcopenia prevalence in the general population was between $12.6 \%$ and $17.5 \%$ [6].

Sarcopenia may be induced by heart failure via common pathogenetic pathways and mechanisms influenced by each other, such as physical activities, malnutrition, and hormonal changes. Prevalence levels are significantly greater in individuals with heart failure (HF), ranging between 19.5 and $47.3 \%$ [7].

Conversely, the development of heart failure may be favored by Sarcopenia via various mechanisms such as pathological ergoreflexes. It can be considered as a paradox that the association of sarcopenia is not visible with a sarcopenic cardiac muscle, while nonfunctional hypertrophy is displayed by cardiac muscles. In addition, cardiac hypertrophy can be considered as the normal mechanism of cardiac adaptation to the conditions of a rise in systemic demand. Cardiac dysfunctions can be caused by a hypertensive state in pregnancy and even in athletes via the heart's physiological hypertrophy or via pathological hypertrophy, which can be triggered by various factors such as hemodynamic stress of irregular and prolonged nature, i.e., a hypertensive condition [4]. Cardiac cachexia has long been shown to be associated with decreased survival and this result can be considered independent of other prognostic variables such as low peak oxygen consumption, age, NYHA (New York Heritage Association) class, or LVEF (left ventricular ejection fraction) [8]. Additionally, research demonstrates a strong link between micronutrients such as $\mathrm{Mg}^{2+}$ and cardiovascular health, and highlights the potential pathophysiological pathways through which $\mathrm{Mg}^{2+}$ depletion may increase the development, progression, and maintenance of CVD. Indeed, hypomagnesemia has a detrimental effect on cardiovascular health, as it is linked with an increased prevalence of hypertension, type 2 diabetes, dyslipidemia, atherosclerosis, arrhythmias, and coronary artery disease [9], all of which are common in sarcopenia [10].

Enhanced muscle reflex has a significant link with peripheral muscle wastage and, additionally, the overactivity of muscle reflex can be considered consistent with the idea that the development of a syndrome is linked to the muscle's peripheral maladaptive changes. There are some important factors, such as progressive age, associated with sarcopenia and the change in gut microbiota diversity. Dysbiosis can also be considered as an independent cardiovascular risk factor and as responsible for heart failure in elderly people. Minimal investigations have been conducted in elderly patients regarding the actual mechanisms, such as concerning cardiac mass alteration and dysfunction, which are considered equivalent with cardiovascular diseases. They can be concluded as the downward spiral of dysregulation regarding exercise of the skeletal muscle, which is suggested by the hypothesis of muscle and can be correlated with certain vicious cycles in heart failure in which, initially, there are adaptive physiological responses that are gradually converted into maladaptive responses [11]. Thus, the purpose of this review is to summarize the existing knowledge about a particular diet including trimethylamine, which 
usually seems to be effective for the improvement of cardiac and skeletal muscle, such as choline and L-carnitine, which may aggravate the HF process in sarcopenic patients.

\section{Consideration of the Sources for the Review of Literature}

Certain databases such as Medline, Mendeley, Google Scholar, Public Library of Science, PubMed, ScienceDirect, and Springer Link were considered and searched through for the literature review, searching for studies that were potentially relevant and in which certain keywords were used both alone and in conjunction. Certain keywords that were significant and were used for the search of literature were 'Sarcopenia', 'Epidemiology of sarcopenia', 'Mechanism of sarcopenia mediated heart failure', 'Involvement of dysbiosis in sarcopenia', 'Pathogenesis of heart failure', 'Reactive oxygen species-mediated mitochondrial dysfunction, 'Relationship of choline and L-carnitine for muscle function improvement' or 'Role of TMA and TMAO in heart failure, in combination with 'heart failure and dysbiosis', 'Immunogenic profile in sarcopenia and heart failure', and 'ergoreflx mechanism in sarcopenia associated heart failure'. In this review, only papers in English were considered. The reference list of the papers found were also screened for related articles not detected by the initial search strategy.

\section{Clinical Characteristics of Sarcopenia in Association with Gut Microbiota Diversity}

Sarcopenia can be referred to as the gradual loss in mass of skeletal muscle, the loss of its strength, and the loss of functions performed, and it is now considered as the major factor of negative effects of health in the later period of life [12]. In fact, the high pervasiveness of chronic health conditions can be correlated with old age (e.g., inflammatory irritable bowel syndrome, celiac disease, autoimmune disease, colitis, diabetes, cancer, cardiovascular disease, neurodegeneration, and so on), which lead in turn to many negative health events (e.g., illness, loss of freedom, institutionalization, underprivileged quality of life, and mortality) [13-15].

The authors established a link between health status, diet, and microbiota. To be more precise, the composition of the microbial population was predominantly influenced by fruit, meat, and vegetable intake. Additionally, a higher proportion of two dominant phyla, namely Firmicutes (64\%) and Bacteroidetes (23\%), comprise up to $90 \%$ of the overall gut microbiota in older people who are living in long-term care facilities [16-18]). It has been identified that the level of Staphylococcus spp. and Lactobacillus Reuters, both of which are from phylum firmicutes, is high in obese people. A positive correlation has been established between plasma $>$ C-reactive protein (CRP) and plasma $[19,20]$. Moreover, older people are primarily affected by a rise in Escherichia (phylum of proteobacteria) abundance [16]. However, it is understood that an increase in gram-negative bacteria such as proteobacteria in their relative abundance is one of the most significant harmful age-changes for the human intestinal microbiota composition, as lipopolysaccharides are secreted by these gram-negative bacteria, through which inflammation can be induced in the intestines [21]. Advancing age can also be characterized by a gastrointestinal microbiota's dysbiosis, which promotes the circulation passage of endotoxin and other microbial products or metabolites via the increased permeability of the intestine [22], thereby highlighting the influential role of gut dysbiosis for deficits in muscle functions associated with age. Sarcopenic patients have increased serum c-reactive protein (CRP) levels, while trials with other inflammatory mediators such as interleukin 6 have not shown consistent results [23].

In addition, the maintenance of sarcopenia is supported by the insufficient nutritional system and aged immune system, which play key roles in stimulating the activation of chronic inflammation [24,25]. In cachexia and sarcopenia, however, mitochondrial and systemic inflammation plays a central role. The proinflammatory role of cytokines (e.g., IL6, IL1 $\beta$, TNF- $\alpha$, and TNF-style weak apoptosis inducer (TWEAK)) has previously been reported in inducting muscle catabolism [26] (Figure 1). 


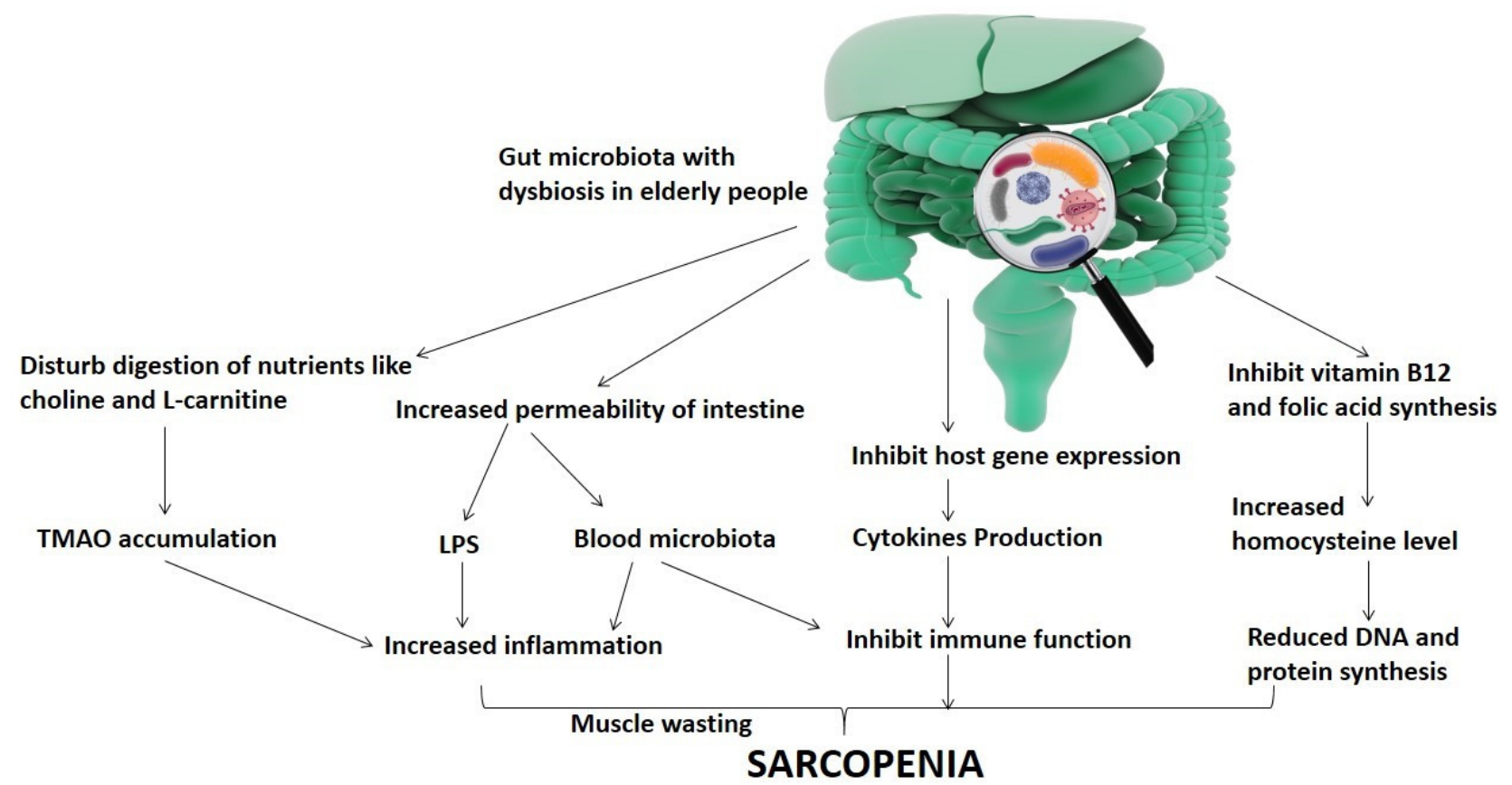

Figure 1. Representation of the relationship of gut microbiota dysbiosis-mediated sarcopenia in elderly people.

\section{Dietary Intake Choline and L-Carnitine-Mediated Aggravation of CVD}

Choline/L-carnitine was investigated as an ergogenic aid for improving the training ability of a stable athletic population due to its pivotal role in the oxidation of fatty acids and energy metabolism. Beneficial impacts on acute physical performance, such as increased power production and increased intake of maximum oxygen, were observed in earlier research studies and further studies show the beneficial influence of L-carnitine as a dietary supplementation in the post-exercise recovery process. L-carnitine has been shown to alleviate the injury of muscles and condenses' cellular damage markers, and muscle soreness attenuation is accompanied by free radical formation [27].

In 2013, researchers first demonstrated that a molecular metabolite, namely trimethylamine-N-oxide (TMAO) isolated from the microbiota of the gut, predicted that 4007 healthy cardiac patients will be enduring elective coronary angiography with an excepted increased risk of cardiovascular accidents [28]. TMAO is produced by microbiota via the ingestion of meat products containing nutritional precursors of trimethylamine, such as phosphatidylcholine, glycerophosphocholine, trimethylglycine, betaine, $\gamma$-butyrobetaine, crotonobetaine, choline, and L-carnitine [28-31]. Specific intestinal microbial enzymes convert these precursors into trimethylamine and to date, they have identified four different types of microbial enzyme systems including choline-TMA lyase (cutC/D) [32], carnitine monooxygenase (cntA/B) [33], betaine reductase [34], and TMAO reductase [35]. Recently, it has also been demonstrated that elevated L-carnitine, choline, and phosphatidylcholine amounts reflect multiple cardiovascular hazards such as myocardial infarction, hypertension, atherosclerosis, and diabetes [36-43].

Change in the microbiota composition of the gut caused by sarcopenia and heart failure can alter the circulating levels of TMAO. Moreover, it has been identified that hypertension patients experience an alteration in intestinal microbiota diversity. Experiments conducted on rats who were treated with angiotensin II revealed that intestinal biota species were less diverse and when compared to regulated rats, the Firmicutes to Bacteroidetes ratio was increased [44,45]. Moreover, heart failure was considered a chronic systemic inflammatory disorder, which indicates a substantial rise in pro-inflammatory cytokines of plasma; although its origin is still unclear, this unresolved inflammation can be considered as one of the key components of cardiovascular diseases [46,47]. Several occurring signs indicate that 
the microbiota of the gut produces bioactive metabolites including bile acids, short chains of fatty acids, and TMAO, and might have systemic effects on the host [48]. Microbiotas and their metabolites affect intestinal health and other physiological processes, especially within the circulatory system. Under normal circumstances, most can be considered as healthy and safe bacterial metabolites, but due to the involvement of heart-failure-related cardiovascular pathologic processes, there is a risk of disruption in the balance of the microbiota of the gut as well as a risk of a rise in the level of harmful metabolites; generally, it was shown in studies that TMAO was found to be related with the prognosis of at-risk heart-failure patients. Moreover, Firmicutes, including Enterococcus, Proteobacteria, Anaerococcus, Streptococcus, and Desulfitobacterium including Actinobacteria, Clostridium, Citrobacter, Dseulfovibrio Enterobacter, Escherichia, Proteus, Pseudomonas, and Klebsiella, have been linked with the production of the primary component of TMAO, i.e., TMA [49].

One research study found that eight Firmicute and Proteobacteria species have absorbed more than $60 \%$ of the production of choline of TMA, including Escherichia fergusonii, Clostridium asparagiforme, C. hathawayi, C. sporogenes, Edwardsiella tarda Anaerococcus hydrogenalis, Proteus penneri, and Providencia rettgeri [50]. Akkermansia, Prevotella, and Sporobacter are some other gut microbiota that are associated with the higher production of TMAO [51], and atherosclerotic CAD is associated with Ruminococcus gnavus [52]. The growth of CAD may be predicted via different metabolites such as betaine, choline, and TMA. It can be explained, for instance, by considering that TMAOproducing microbes can be reduced by blocking or inhibiting specific microbial metabolic pathways via utilizing pharmacological intervention and probiotics [53]. Furthermore, the increased level of Ruminococcus is due to the high fat and high protein diet [54], and additionally, downregulation of Treg cells is led by TLR4 activation, which is associated with inflammatory responses such as CD4, Pro-inflammatory cytokines, and Th1 and T cells $[55,56]$. Thus, we explore, from top to bottom, all of the contributing factors associated with CVD.

\section{Pathobiological Interactions in Heart Failure Involving TMAO}

Mechanisms of heart failure pathophysiological pathways are quite intricate and include inflammatory reaction, hemodynamics irregularity, cardiac remodeling, neuroendocrine system stimulation, etc. Traditionally, the key causes of heart failure are supposed to be the activation of the pathways of the neuroendocrine system, which include the natriuretic peptide system, renin-angiotensin-aldosterone cascade, and sympathetic nervous system, which lead to a pathologic myocardial remodeling process series including apoptosis, extracellular matrix deposition, myocardial hypertrophy, and resultant fibrosis $[57,58]$. Hence, neuroendocrine inhibition is the main basis of the strategies of current treatments [59]. Mechanisms driving the development and progression of heart failure are, however, still under consideration. In the conversion of dietary choline into the intermediate trimethylamine (TMA), a requisite role is played by microbiota of the gut and TMAO is formed by the subsequent oxidization of TMA after it enters into the circulatory system by the flavin-containing monooxygenase (FMO) enzyme, which is encoded by the FMO gene present in the kidney, liver, and in many other tissues [60,61]. There is an increase in the permeability of the intestinal barrier via two mechanisms in the condition of heart failure, in which during the initial stage, a decreased inflow of blood to the intestinal endothelium is observed, and via the ischemia of the wall of the intestine, there is an increase in the permeability of the intestinal epithelial barrier [62]. Due to the intestinal wall's congestion and swelling in the advanced stages of heart failure, there is an increase in the permeability of the intestine. Additionally, in the patients identified with chronic heart failure, higher levels of enteropathogenic candida, such as Campylobacter, Shigella, and Salmonella, were observed [63]. This process is directly linked with microbial and microbial metabolite translocation [64,65]. Recent research evidence indicates that chronic inflammation can be caused by both an increase in the permeability and an increase in the disordered microbiota of the intestine, further leading to impaired 
cardiac function $[62,66]$. In addition, studies have shown that there are severe clinical symptoms and worse survival rates associated with patients with heart failure, which are due to the elevated serum levels of multiple cytokines, such as IL-1, IL-6, and the TNF [67-69]. This is consistent with findings that both heart failure and sarcopenic patients have an elevated proportion of these bacterial strains of the intestine, indicating shifts in intestinal microbiota, which may influence levels of TMAO by controlling intestinal TMA synthesis. TMAO has recently become a major mediator showing that the microbiota of the gut has a close relationship with several CVDs. Subsequent preclinical experiments explored the evidence concerning that the heart is directly affected by the TMAO, inducing endothelial cell and vascular inflammation, fibrosis and myocardial hypertrophy, and heart mitochondrial dysfunction, thus aggravating the heart-failure process [70-72]. In addition, the association of TMAO is established with both the C-reactive protein (CRP) and with endothelial dysfunction in evaluating the increased permeability of the gut, and is closely related to increased LPS endotoxin serum levels [49], leading to the release of calcium and the hyperreactivity of the platelets [73], contributing to the aggravation of heart failure. The several key pathophysiological pathways of TMAO include the following: explicitly and implicitly contributing in heart failure, including through the pathological LV dilation of the mouse-fed TMAO or choline-demonstrated decreased LVEF, and enhanced circulatory BNP volumes, myocardial fibrosis, and lung oedema [31]; TMAO-encouraged myocardial hypertrophy and fibrosis through Smad3 signals [71]; cardiac remodeling attenuated through 3,3-dimethyl-1-butanol via the reduction in the volume of plasma TMAO, which modifies the signals of TGF- $\beta 1 / \operatorname{Smad} 3$ and p 65 NF-kB [74]; TMAO-promoted activated leukocyte recruitment into endothelial cells and induced inflammatory gene expression via the activation of NF-kB signaling [75]; TMAO significantly affected the contractile nature of cardiomyocyte and intracellular calcium-handling in the negative direction [76]; Pyruvates and fatty acid oxidation in cardiac mitochondria is influenced by TMAO [70]; and, last but not least, TMAO stimulated vascular inflammation by triggering the inflammatory NLRP3 induced by inhibiting SIRT3-SOD2-mitochondrial ROS signaling pathway [77]. Moreover, the function of TMAO, as first assessed by Suzuki et al. [78] in acute HF (AHF), was found to be a predicting marker for mortality and mortality/heart failure within a year (Table 1) [79].

Table 1. TMA metabolism-targeting therapeutic methods.

\begin{tabular}{|c|c|c|}
\hline Therapy & Alteration in Biotransformation TMA & Implications \\
\hline $\begin{array}{l}\text { Inhibition of the } \\
\text { FMO3 enzyme }\end{array}$ & Prevents oxidation of TMA to TMAO & $\begin{array}{l}\text { Trimethylaminuria is caused by an accumulation } \\
\text { of TMA and is characterized by a fishy odor. It } \\
\text { may also cause inflammation. Additionally, FMO3 } \\
\text { metabolizes a wide variety of other compounds. }\end{array}$ \\
\hline Resveratrol & $\begin{array}{l}\text { Modifies the makeup of the gut microbiota. } \\
\text { Reduces the formation of TMA and TMAO }\end{array}$ & $\begin{array}{l}\text { Increases Lactobacillus and Bifidobacterium. When } \\
\text { antibiotics are taken, no adverse effects occur. } \\
\text { Observed in mice studies. }\end{array}$ \\
\hline Enalapril & Increases TMAO excretion in the urine & $\begin{array}{l}\text { Mechanism unknown. Rat studies were conducted. } \\
\text { It does not affect TMA synthesis or the makeup of } \\
\text { the gut flora. }\end{array}$ \\
\hline Prebiotics & $\begin{array}{l}\text { Induces a beneficial effect on the makeup of the } \\
\text { gut bacteria to reduce TMA production } \\
\text { in the intestine }\end{array}$ & $\begin{array}{l}\text { In humans, the consequences are unknown. } \\
\text { Numerous variables affect the makeup of } \\
\text { the gut microbiota. }\end{array}$ \\
\hline $\begin{array}{l}\text { Probiotics (I): } \\
\text { Methanogenic bacteria }\end{array}$ & Reduces TMA and TMAO levels & Human safety and engraftment are unknown. \\
\hline $\begin{array}{l}\text { Probiotics (II): Bacteria } \\
\text { incapable of converting } \\
\text { precursors to TMA }\end{array}$ & Reduces the production of TMA in the gut & $\begin{array}{l}\text { Mice show beneficial benefits. However, the } \\
\text { consequences on people remain unknown. }\end{array}$ \\
\hline
\end{tabular}


Table 1. Cont.

\begin{tabular}{ccc}
\hline Therapy & Alteration in Biotransformation TMA & Implications \\
\hline Meldonium & $\begin{array}{c}\text { Reduces the production of TMAO from } \\
\text { L-carnitine (GBB conversion to L-carnitine } \\
\text { is inhibited) }\end{array}$ & $\begin{array}{c}\text { TMAO production from choline cannot be reduced. } \\
\text { It may result in a rise in the urine excretion of } \\
\text { TMAO in people. }\end{array}$ \\
\hline $\begin{array}{c}\text { Oral non-absorbent } \\
\text { binders }\end{array}$ & $\begin{array}{c}\text { Eliminates TMAO or any of its precursors from } \\
\text { the gut }\end{array}$ & $\begin{array}{c}\text { A speculative approach. There has not yet been } \\
\text { found a chemical capable of removing } \\
\text { TMAO specifically. }\end{array}$ \\
\hline
\end{tabular}

Additionally, an independent cohort of ambulatory individuals with persistent systolic HF supports our results and provides new insights on the link between the three phosphatidylcholine metabolic isomers, namely TMAO, choline, and betaine, considering echocardiographic determinants and the associations between both renal and inflammatory biomarkers. Numerous noteworthy discoveries have been made. To begin, we found that TMAO had a superior predictive value to choline and betaine in patients with chronic systolic heart failure, regardless of the cardio-renal parameters. Second, rather than LV systolic dysfunction, we found associations between all three metabolites and LV diastolic dysfunction. Thirdly, the very low correlations between TMAO, choline, and betaine in many well-characterized inflammatory biomarkers and in their distinct associations with endothelial dysfunction indicators indicated the existence of a separate pathophysiological mechanism. Notably, the increased TMAO levels seen in individuals with renal insufficiency or diabetes mellitus suggest an underlying metabolic deficiency associated with those disease states rather than a systemic inflammatory response. Nonetheless, the relationship between increased TMAO and both HF severity and adverse outcomes, irrespective of other cardio-renal indices, argues for a possible harmful molecular link between the gut microbiota pathway that generates TMAO and the development and/or progression of HF. Notably, this is a cohort of ambulatory stable heart failure patients with left ventricular systolic dysfunction and with an annualized mortality of $7.1 \%$ (considering transplantation as the equivalent of death), which is not dissimilar to that seen in published clinical trials. Taken together, our results validate the clinical relevance of TMAO levels in heart failure and indicate that further research is needed to elucidate the association's molecular underpinnings. However, after tuning for the parameters of renal function, the capacity of the TMAO to independently forecast is lost, likely due to the substantial correlations between the parameters of renal function (approximate glomerular filtration rate and urea) and TMAO. These findings indicate that a higher degree of "backward failure" (congestion associated with scarring or ischemia) rather than "forward failure" (or reduced perfusion) may be linked with the main metabolic deficiency underlying the observed correlations. Consistent with this, correlations between choline and renal function indices were seen for both choline and TMAO, although the link between TMAO and adverse outcomes in individuals persisted even after adjusting for renal function. The purpose of this study was to investigate the connection between (1) the intestinal microbiota-dependent analyte TMAO and its dietary precursors, namely and choline and betaine, and (2) echocardiographic indicators in sarcopenic patients with chronic systolic heart failure $[80,81]$ (Figure 2). 


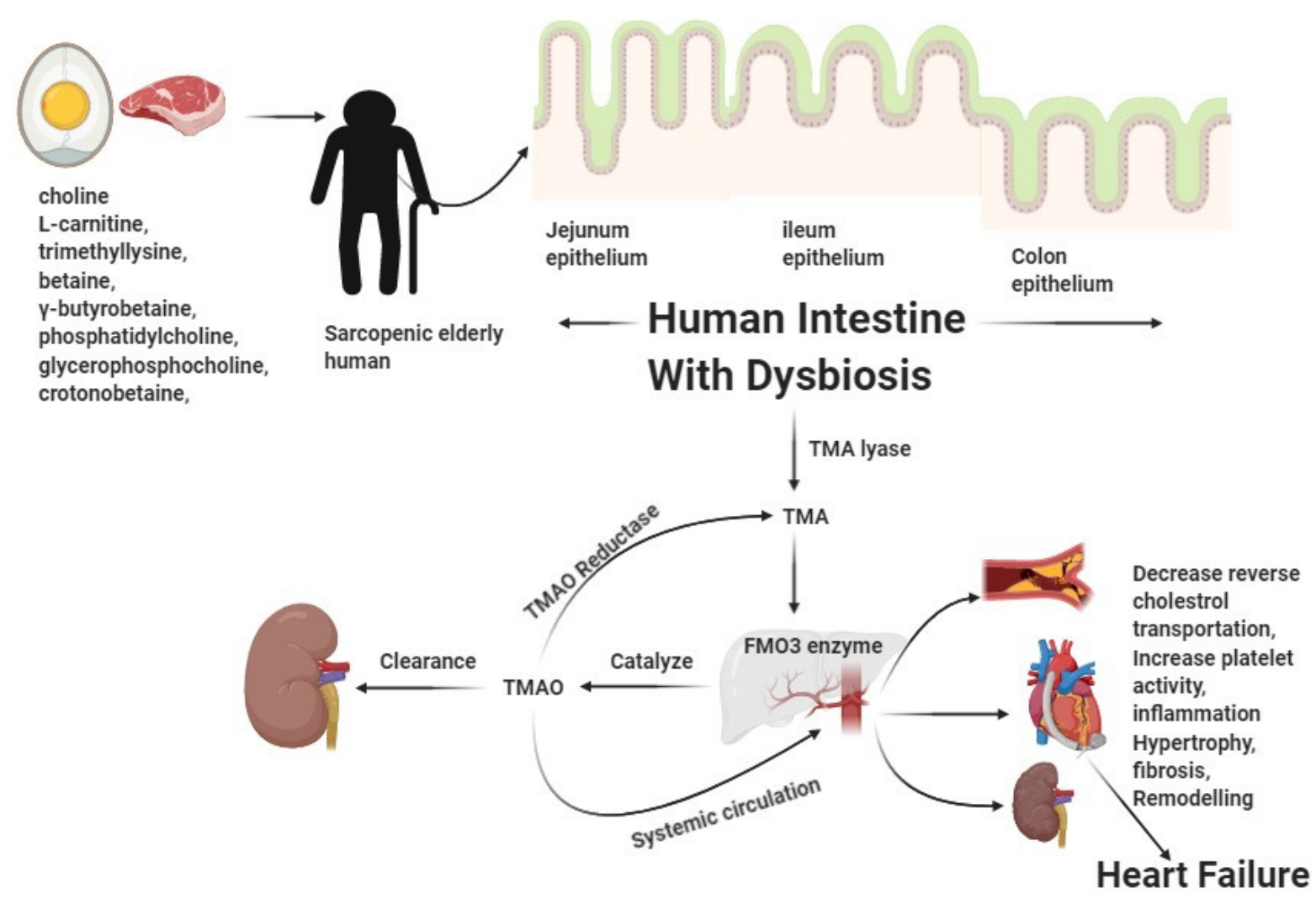

Figure 2. Representation demonstrating the pathobiological relationship of the excessive intake of choline/L-carnitinecontaining diet-associated TMAO accumulation, resulting in the heart failure of sarcopenic patients.

\section{Conclusions}

Sarcopenia is common in cases of heart failure, leading to inadequate disease prognosis. While the pathophysiology of muscle wastage is quite complicated in heart failure, multiple pathogenetic mechanisms tend to be shared by sarcopenia and heart failure, and they can benefit from strategies of standard treatment focused on a nutritional, physical, and pharmacological approach. In recent years, several studies have identified a clear correlation between CVDs and the microbiota of the gut. We already know that TMAO, a gut microbiota metabolite, may have fresh perspectives and insights regarding how heart failure is supported by the microbiota of the gut. These findings provide a good opportunity for controlling heart failure via addressing the microbiota of the gut, including through the use of updated probiotics, prebiotics, dietary therapy, and FMT. Moreover, emerging research from different groups and clinical findings reveal the association between the dysfunction of the microbiota of the gut, the TMAO circulation, and the susceptibility of heart failure, indicating a fresh and desirable therapeutic target for HF treatment. Furthermore, excessive intake of a diet such as choline or L-carnitine, which contain intermediate precursor TMA for TMAO, should be carefully used in elderly people who have dysbiosis with muscle disorders. Future research studies are warranted.

Author Contributions: Conceptualization and methodology, I.K. and M.N.B.-J.; writing-original draft preparation, S.J.G., S.H., F.A.A.-A. and I.K.; writing-review and editing, S.S.I., M.Z. and M.S.N.; supervision, S.A. and M.M.G.; project administration, I.K. All authors have read and agreed to the published version of the manuscript.

Funding: This research received no external funding.

Acknowledgments: Authors are thankful for Deanship of Library Affairs, King Abdulaziz University for providing online access of articles.

Conflicts of Interest: The authors declare no conflict of interest. 


\section{References}

1. Wu, G.D.; Bushmanc, F.D.; Lewis, J.D. Diet, the human gut microbiota, and IBD. Anaerobe 2013, 24, 117-120. [CrossRef]

2. Kazemian, N.; Mahmoudi, M.; Halperin, F.; Wu, J.C.; Pakpour, S. Gut microbiota and cardiovascular disease: Opportunities and challenges. Microbiome 2020, 8, 36. [CrossRef]

3. Wu, G.D.; Chen, J.; Hoffmann, C.; Bittinger, K.; Chen, Y.Y.; Keilbaugh, S.A.; Bewtra, M.; Knights, D.; Walters, W.A.; Knight, R.; et al. Linking long-term dietary patterns with gut microbial enterotypes. Science 2011, 334, 105-108. [CrossRef] [PubMed]

4. Shimizu, I.; Minamino, T. Physiological and pathological cardiac hypertrophy. J. Mol. Cell. Cardiol. 2016, 97, 245-262. [CrossRef] [PubMed]

5. von Haehling, S.; Morley, J.E.; Anker, S.D. An overview of sarcopenia: Facts and numbers on prevalence and clinical impact. J. Cachexia Sarcopenia Muscle 2010, 1, 129-133. [CrossRef] [PubMed]

6. Tyrovolas, S.; Koyanagi, A.; Olaya, B.; Ayuso-Mateos, J.L.; Miret, M.; Chatterji, S.; Tobiasz-Adamczyk, B.; Koskinen, S.; Leonardi, M.; Haro, J.M. Factors associated with skeletal muscle mass, sarcopenia, and sarcopenic obesity in older adults: A multi-continent study. J. Cachexia Sarcopenia Muscle 2016, 7, 312-321. [CrossRef]

7. Hajahmadi, M.; Shemshadi, S.; Khalilipur, E.; Amin, A.; Taghavi, S.; Maleki, M.; Malek, H.; Naderi, N. Muscle wasting in young patients with dilated cardiomyopathy. J. Cachexia Sarcopenia Muscle 2017, 8, 542-548. [CrossRef]

8. Anker, S.D.; Ponikowski, P.; Varney, S.; Chua, T.P.; Clark, A.L.; Webb-Peploe, K.M.; Harrington, D.; Kox, W.J.; Poole-Wilson, P.A.; Coats, A.J. Wasting as independent risk factor for mortality in chronic heart failure. Lancet 1997, 349, 1050-1053. [CrossRef]

9. Severino, P.; Netti, L.; Mariani, M.V.; Maraone, A.; D’Amato, A.; Scarpati, R.; Infusino, F.; Pucci, M.; Lavalle, C.; Maestrini, C.; et al. Prevention of Cardiovascular Disease: Screening for Magnesium Deficiency. Cardiol. Res. Pract. 2019, 2019, 4874921. [CrossRef] [PubMed]

10. Dominguez, L.J.; Barbagallo, M.; Lauretani, F.; Bandinelli, S.; Bos, A.; Corsi, A.M.; Simonsick, E.M.; Ferrucci, L. Magnesium and muscle performance in older persons: The InCHIANTI study. Am. J. Clin. Nutr. 2006, 84, 419-426. [CrossRef] [PubMed]

11. Piepoli, M.F.; Kaczmarek, A.; Francis, D.P.; Davies, L.C.; Rauchhaus, M.; Jankowska, E.A.; Anker, S.D.; Capucci, A.; Banasiak, W.; Ponikowski, P. Reduced Peripheral Skeletal Muscle Mass and Abnormal Reflex Physiology in Chronic Heart Failure. Circulation 2006, 114, 126-134. [CrossRef] [PubMed]

12. Marzetti, E.; Calvani, R.; Tosato, M.; Cesari, M.; Di Bari, M.; Cherubini, A.; Collamati, A.; D’Angelo, E.; Pahor, M.; Bernabei, R.; et al. Sarcopenia: An overview. Aging Clin. Exp. Res. 2017, 29, 11-17. [CrossRef] [PubMed]

13. Cesari, M.; Marzetti, E.; Thiem, U.; Pérez-Zepeda, M.U.; Abellan Van Kan, G.; Landi, F.; Petrovic, M.; Cherubini, A.; Bernabei, R. The geriatric management of frailty as paradigm of "The end of the disease era". Eur. J. Intern. Med. 2016, 31, 11-14. [CrossRef] [PubMed]

14. Arumugam, M.; Raes, J.; Pelletier, E.; Le Paslier, D.; Yamada, T.; Mende, D.R.; Fernandes, G.R.; Tap, J.; Bruls, T.; Batto, J.M.; et al. Enterotypes of the human gut microbiome. Nature 2011, 473, 174-180. [CrossRef] [PubMed]

15. Saraswati, S.; Sitaraman, R. Aging and the human gut microbiota-from correlation to causality. Front. Microbiol. 2015, 5, 764. [CrossRef]

16. Claesson, M.J.; Jeffery, I.B.; Conde, S.; Power, S.E.; O'Connor, E.M.; Cusack, S.; Harris, H.M.; Coakley, M.; Lakshminarayanan, B.; O'Sullivan, O.; et al. Gut microbiota composition correlates with diet and health in the elderly. Nature 2012, 488, 178-184. [CrossRef] [PubMed]

17. Huttenhower, C.; Gevers, D.; Knight, R.; Abubucker, S.; Badger, J.H.; Chinwalla, A.T.; Creasy, H.H.; Earl, A.M.; FitzGerald, M.G.; Fulton, R.S.; et al. Structure, function and diversity of the healthy human microbiome. Nature 2012, 486, 207-214. [CrossRef]

18. Dethlefsen, L.; McFall-Ngai, M.; Relman, D.A. An ecological and evolutionary perspective on human-microbe mutualism and disease. Nature 2007, 449, 811-818. [CrossRef] [PubMed]

19. Bervoets, L.; Van Hoorenbeeck, K.; Kortleven, I.; Van Noten, C.; Hens, N.; Vael, C.; Goossens, H.; Desager, K.N.; Vankerckhoven, V. Differences in gut microbiota composition between obese and lean children: A cross-sectional study. Gut Pathog. $2013,5,10$. [CrossRef]

20. Million, M.; Angelakis, E.; Paul, M.; Armougom, F.; Leibovici, L.; Raoult, D. Comparative meta-analysis of the effect of Lactobacillus species on weight gain in humans and animals. Microb. Pathog. 2012, 53, 100-108. [CrossRef]

21. Kumar, M.; Babaei, P.; Ji, B.; Nielsen, J. Human gut microbiota and healthy aging: Recent developments and future prospective. Nutr. Healthy Aging 2016, 4, 3-16. [CrossRef] [PubMed]

22. Pitchumoni, C.; Mishra, S.P.; Yadav, H. Gut Microbiota and Aging: A Broad Perspective. In Geriatric Gastroenterology; Pitchumoni, C.S., Dharmarajan, T.S., Eds.; Springer International Publishing: Cham, Switzerland, 2020; pp. 1-21. [CrossRef]

23. Bano, G.; Trevisan, C.; Carraro, S.; Solmi, M.; Luchini, C.; Stubbs, B.; Manzato, E.; Sergi, G.; Veronese, N. Inflammation and sarcopenia: A systematic review and meta-analysis. Maturitas 2017, 96, 10-15. [CrossRef] [PubMed]

24. Ticinesi, A.; Meschi, T.; Lauretani, F.; Felis, G.; Franchi, F.; Pedrolli, C.; Barichella, M.; Benati, G.; Di Nuzzo, S.; Ceda, G.P.; et al. Nutrition and Inflammation in Older Individuals: Focus on Vitamin D, n-3 Polyunsaturated Fatty Acids and Whey Proteins. Nutrients 2016, 8, 186. [CrossRef] [PubMed]

25. Wilson, D.; Jackson, T.; Sapey, E.; Lord, J.M. Frailty and sarcopenia: The potential role of an aged immune system. Ageing Res. Rev. 2017, 36, 1-10. [CrossRef] 
26. Zhou, J.; Liu, B.; Liang, C.; Li, Y.; Song, Y.H. Cytokine Signaling in Skeletal Muscle Wasting. Trends Endocrinol. Metab. TEM 2016, 27, 335-347. [CrossRef] [PubMed]

27. Fielding, R.; Riede, L.; Lugo, J.P.; Bellamine, A. 1-Carnitine Supplementation in Recovery after Exercise. Nutrients 2018, 10, 349. [CrossRef] [PubMed]

28. Wang, Z.; Klipfell, E.; Bennett, B.J.; Koeth, R.; Levison, B.S.; Dugar, B.; Feldstein, A.E.; Britt, E.B.; Fu, X.; Chung, Y.M.; et al. Gut flora metabolism of phosphatidylcholine promotes cardiovascular disease. Nature 2011, 472, 57-63. [CrossRef]

29. Tang, W.H.; Hazen, S.L. The contributory role of gut microbiota in cardiovascular disease. J. Clin. Investig. 2014, $124,4204-4211$. [CrossRef]

30. Wang, Z.; Zhao, Y. Gut microbiota derived metabolites in cardiovascular health and disease. Protein Cell. 2018, 9, 416-431. [CrossRef]

31. Organ, C.L.; Otsuka, H.; Bhushan, S.; Wang, Z.; Bradley, J.; Trivedi, R.; Polhemus, D.J.; Tang, W.H.; Wu, Y.; Hazen, S.L.; et al. Choline Diet and Its Gut Microbe-Derived Metabolite, Trimethylamine N-Oxide, Exacerbate Pressure Overload-Induced Heart Failure. Circ. Heart Fail. 2016, 9, e002314. [CrossRef]

32. Craciun, S.; Marks, J.A.; Balskus, E.P. Characterization of choline trimethylamine-lyase expands the chemistry of glycyl radical enzymes. ACS Chem. Biol. 2014, 9, 1408-1413. [CrossRef] [PubMed]

33. Zhu, Y.; Jameson, E.; Crosatti, M.; Schäfer, H.; Rajakumar, K.; Bugg, T.D.; Chen, Y. Carnitine metabolism to trimethylamine by an unusual Rieske-type oxygenase from human microbiota. Proc. Natl. Acad. Sci. USA 2014, 111, 4268-4273. [CrossRef]

34. Andreesen, J.R. Glycine metabolism in anaerobes. Antonie Van Leeuwenhoek 1994, 66, 223-237. [CrossRef] [PubMed]

35. Pascal, M.C.; Burini, J.F.; Chippaux, M. Regulation of the trimethylamine N-oxide (TMAO) reductase in Escherichia coli: Analysis of tor::Mud1 operon fusion. Mol. Gen. Genet. MGG 1984, 195, 351-355. [CrossRef] [PubMed]

36. Yang, Q.; Liang, Q.; Balakrishnan, B.; Belobrajdic, D.P.; Feng, Q.J.; Zhang, W. Role of Dietary Nutrients in the Modulation of Gut Microbiota: A Narrative Review. Nutrients 2020, 12, 381. [CrossRef] [PubMed]

37. Rowland, I.; Gibson, G.; Heinken, A.; Scott, K.; Swann, J.; Thiele, I.; Tuohy, K. Gut microbiota functions: Metabolism of nutrients and other food components. Eur. J. Nutr. 2018, 57, 1-24. [CrossRef] [PubMed]

38. Tang, W.H.; Wang, Z.; Levison, B.S.; Koeth, R.A.; Britt, E.B.; Fu, X.; Wu, Y.; Hazen, S.L. Intestinal microbial metabolism of phosphatidylcholine and cardiovascular risk. N. Engl. J. Med. 2013, 368, 1575-1584. [CrossRef]

39. Senthong, V.; Wang, Z.; Fan, Y.; Wu, Y.; Hazen, S.L.; Tang, W.H.W. Trimethylamine N-oxide and mortality risk in patients with peripheral artery disease. J. Am. Heart Assoc. 2016, 5, e004237. [CrossRef]

40. Ge, X.; Zheng, L.; Zhuang, R.; Yu, P.; Xu, Z.; Liu, G.; Xi, X.; Zhou, X.; Fan, H. The Gut Microbial Metabolite Trimethylamine N-Oxide and Hypertension Risk: A Systematic Review and Dose-Response Meta-analysis. Adv. Nutr. 2020, 11, 66-76. [CrossRef]

41. Tan, Y.; Sheng, Z.; Zhou, P.; Liu, C.; Zhao, H.; Song, L.; Li, J.; Zhou, J.; Chen, Y.; Wang, L.; et al. Plasma Trimethylamine N-Oxide as a Novel Biomarker for Plaque Rupture in Patients With ST-Segment-Elevation Myocardial Infarction. Circ. Cardiovasc. Interv. 2019, 12, e007281. [CrossRef]

42. Ivashkin, V.T.; Kashukh, Y.A. Impact of L-carnitine and phosphatidylcholine containing products on the proatherogenic metabolite TMAO production and gut microbiome changes in patients with coronary artery disease. Vopr. Pitan. 2019, 88, 25-33. [CrossRef] [PubMed]

43. Tang, W.H.; Wang, Z.; Li, X.S.; Fan, Y.; Li, D.S.; Wu, Y.; Hazen, S.L. Increased Trimethylamine N-Oxide Portends High Mortality Risk Independent of Glycemic Control in Patients with Type 2 Diabetes Mellitus. Clin. Chem. 2017, 63, 297-306. [CrossRef] [PubMed]

44. Ramezani, A.; Raj, D.S. The gut microbiome, kidney disease, and targeted interventions. J. Am. Soc. Nephrol. JASN 2014, 25, 657-670. [CrossRef]

45. Pluznick, J.L.; Protzko, R.J.; Gevorgyan, H.; Peterlin, Z.; Sipos, A.; Han, J.; Brunet, I.; Wan, L.X.; Rey, F.; Wang, T.; et al. Olfactory receptor responding to gut microbiota-derived signals plays a role in renin secretion and blood pressure regulation. Proc. Natl. Acad. Sci. USA 2013, 110, 4410-4415. [CrossRef] [PubMed]

46. Liljestrand, J.M.; Paju, S.; Pietiäinen, M.; Buhlin, K.; Persson, G.R.; Nieminen, M.S.; Sinisalo, J.; Mäntylä, P.; Pussinen, P.J. Immunologic burden links periodontitis to acute coronary syndrome. Atherosclerosis 2018, 268, 177-184. [CrossRef]

47. Pullen, A.B.; Jadapalli, J.K.; Rhourri-Frih, B.; Halade, G.V. Re-evaluating the causes and consequences of non-resolving inflammation in chronic cardiovascular disease. Heart Fail. Rev. 2020, 25, 381-391. [CrossRef]

48. Tang, W.H.W.; Li, D.Y.; Hazen, S.L. Dietary metabolism, the gut microbiome, and heart failure. Nat. Rev. Cardiol. 2019, 16, 137-154. [CrossRef] [PubMed]

49. Al-Obaide, M.A.I.; Singh, R.; Datta, P.; Rewers-Felkins, K.A.; Salguero, M.V.; Al-Obaidi, I.; Kottapalli, K.R.; Vasylyeva, T.L. Gut Microbiota-Dependent Trimethylamine-N-oxide and Serum Biomarkers in Patients with T2DM and Advanced CKD. J. Clin. Med. 2017, 6, 86. [CrossRef] [PubMed]

50. Liu, T.-X.; Niu, H.-T.; Zhang, S.-Y. Intestinal Microbiota Metabolism and Atherosclerosis. Chin. Med. J. 2015, 128, 2805-2811. [CrossRef] [PubMed]

51. Falony, G.; Vieira-Silva, S.; Raes, J. Microbiology Meets Big Data: The Case of Gut Microbiota-Derived Trimethylamine. Annu. Rev. Microbiol. 2015, 69, 305-321. [CrossRef] 
52. Wang, Z.; Roberts, A.B.; Buffa, J.A.; Levison, B.S.; Zhu, W.; Org, E.; Gu, X.; Huang, Y.; Zamanian-Daryoush, M.; Culley, M.K.; et al. Non-lethal Inhibition of Gut Microbial Trimethylamine Production for the Treatment of Atherosclerosis. Cell 2015, 163, 1585-1595. [CrossRef]

53. Martin, F.P.; Wang, Y.; Sprenger, N.; Yap, I.K.; Lundstedt, T.; Lek, P.; Rezzi, S.; Ramadan, Z.; van Bladeren, P.; Fay, L.B.; et al. Probiotic modulation of symbiotic gut microbial-host metabolic interactions in a humanized microbiome mouse model. Mol. Syst. Biol. 2008, 4, 157. [CrossRef]

54. Kim, K.A.; Gu, W.; Lee, I.A.; Joh, E.H.; Kim, D.H. High fat diet-induced gut microbiota exacerbates inflammation and obesity in mice via the TLR4 signaling pathway. PLoS ONE 2012, 7, e47713. [CrossRef]

55. Feuerer, M.; Herrero, L.; Cipolletta, D.; Naaz, A.; Wong, J.; Nayer, A.; Lee, J.; Goldfine, A.B.; Benoist, C.; Shoelson, S.; et al. Lean, but not obese, fat is enriched for a unique population of regulatory T cells that affect metabolic parameters. Nat. Med. 2009, 15, 930-939. [CrossRef]

56. Ilan, Y.; Maron, R.; Tukpah, A.M.; Maioli, T.U.; Murugaiyan, G.; Yang, K.; Wu, H.Y.; Weiner, H.L. Induction of regulatory T cells decreases adipose inflammation and alleviates insulin resistance in ob/ob mice. Proc. Natl. Acad. Sci. USA 2010, 107, 9765-9770. [CrossRef]

57. Mudd, J.O.; Kass, D.A. Tackling heart failure in the twenty-first century. Nature 2008, 451, 919-928. [CrossRef]

58. Shah, A.M.; Mann, D.L. In search of new therapeutic targets and strategies for heart failure: Recent advances in basic science. Lancet 2011, 378, 704-712. [CrossRef]

59. Ponikowski, P.; Voors, A.A.; Anker, S.D.; Bueno, H.; Cleland, J.G.F.; Coats, A.J.S.; Falk, V.; González-Juanatey, J.R.; Harjola, V.P.; Jankowska, E.A.; et al. 2016 ESC Guidelines for the Diagnosis and Treatment of Acute and Chronic Heart Failure. Rev. Esp. Cardiol. 2016, 69, 1167. [CrossRef] [PubMed]

60. Hernandez, D.; Janmohamed, A.; Chandan, P.; Phillips, I.R.; Shephard, E.A. Organization and evolution of the flavin-containing monooxygenase genes of human and mouse: Identification of novel gene and pseudogene clusters. Pharmacogenetics 2004, 14, 117-130. [CrossRef] [PubMed]

61. Phillips, I.R.; Dolphin, C.T.; Clair, P.; Hadley, M.R.; Hutt, A.J.; McCombie, R.R.; Smith, R.L.; Shephard, E.A. The molecular biology of the flavin-containing monooxygenases of man. Chem.-Biol. Interact. 1995, 96, 17-32. [CrossRef]

62. Sandek, A.; Bauditz, J.; Swidsinski, A.; Buhner, S.; Weber-Eibel, J.; von Haehling, S.; Schroedl, W.; Karhausen, T.; Doehner, W.; Rauchhaus, M.; et al. Altered intestinal function in patients with chronic heart failure. J. Am. Coll. Cardiol. 2007, 50, 1561-1569. [CrossRef]

63. Pasini, E.; Aquilani, R.; Testa, C.; Baiardi, P.; Angioletti, S.; Boschi, F.; Verri, M.; Dioguardi, F. Pathogenic Gut Flora in Patients with Chronic Heart Failure. JACC. Heart Fail. 2016, 4, 220-227. [CrossRef]

64. Bordalo Tonucci, L.; Dos Santos, K.M.; De Luces Fortes Ferreira, C.L.; Ribeiro, S.M.; De Oliveira, L.L.; Martino, H.S. Gut microbiota and probiotics: Focus on diabetes mellitus. Crit. Rev. Food Sci. Nutr. 2017, 57, 2296-2309. [CrossRef] [PubMed]

65. Wang, F.; Jiang, H.; Shi, K.; Ren, Y.; Zhang, P.; Cheng, S. Gut bacterial translocation is associated with microinflammation in end-stage renal disease patients. Nephrology 2012, 17, 733-738. [CrossRef]

66. Cox, A.J.; West, N.P.; Cripps, A.W. Obesity, inflammation, and the gut microbiota. Lancet Diabetes Endocrinol. 2015, 3, 207-215. [CrossRef]

67. Conraads, V.M.; Bosmans, J.M.; Schuerwegh, A.J.; Goovaerts, I.; De Clerck, L.S.; Stevens, W.J.; Bridts, C.H.; Vrints, C.J. Intracellular monocyte cytokine production and CD 14 expression are up-regulated in severe vs mild chronic heart failure. J. Heart Lung Transplant. Off. Publ. Int. Soc. Heart Transplant. 2005, 24, 854-859. [CrossRef] [PubMed]

68. Rauchhaus, M.; Doehner, W.; Francis, D.P.; Davos, C.; Kemp, M.; Liebenthal, C.; Niebauer, J.; Hooper, J.; Volk, H.D.; Coats, A.J.; et al. Plasma cytokine parameters and mortality in patients with chronic heart failure. Circulation 2000, 102, 3060-3067. [CrossRef]

69. Deswal, A.; Petersen, N.J.; Feldman, A.M.; Young, J.B.; White, B.G.; Mann, D.L. Cytokines and cytokine receptors in advanced heart failure: An analysis of the cytokine database from the Vesnarinone trial (VEST). Circulation 2001, 103, 2055-2059. [CrossRef] [PubMed]

70. Makrecka-Kuka, M.; Volska, K.; Antone, U.; Vilskersts, R.; Grinberga, S.; Bandere, D.; Liepinsh, E.; Dambrova, M. Trimethylamine N-oxide impairs pyruvate and fatty acid oxidation in cardiac mitochondria. Toxicol. Lett. 2017, 267, 32-38. [CrossRef] [PubMed]

71. Li, Z.; Wu, Z.; Yan, J.; Liu, H.; Liu, Q.; Deng, Y.; Ou, C.; Chen, M. Gut microbe-derived metabolite trimethylamine N-oxide induces cardiac hypertrophy and fibrosis. Lab. Investig. J. Tech. Methods Pathol. 2019, 99, 346-357. [CrossRef] [PubMed]

72. Sun, X.; Jiao, X.; Ma, Y.; Liu, Y.; Zhang, L.; He, Y.; Chen, Y. Trimethylamine N-oxide induces inflammation and endothelial dysfunction in human umbilical vein endothelial cells via activating ROS-TXNIP-NLRP3 inflammasome. Biochem. Biophys. Res. Commun. 2016, 481, 63-70. [CrossRef] [PubMed]

73. Zhu, W.; Gregory, J.C.; Org, E.; Buffa, J.A.; Gupta, N.; Wang, Z.; Li, L.; Fu, X.; Wu, Y.; Mehrabian, M.; et al. Gut Microbial Metabolite TMAO Enhances Platelet Hyperreactivity and Thrombosis Risk. Cell 2016, 165, 111-124. [CrossRef]

74. Wang, G.; Kong, B.; Shuai, W.; Fu, H.; Jiang, X.; Huang, H. 3,3-Dimethyl-1-butanol attenuates cardiac remodeling in pressureoverload-induced heart failure mice. J. Nutr. Biochem. 2020, 78, 108341. [CrossRef]

75. Seldin, M.M.; Meng, Y.; Qi, H.; Zhu, W.; Wang, Z.; Hazen, S.L.; Lusis, A.J.; Shih, D.M. Trimethylamine N-Oxide Promotes Vascular Inflammation Through Signaling of Mitogen-Activated Protein Kinase and Nuclear Factor-кB. J. Am. Heart Assoc. 2016, 5, e002767. [CrossRef] 
76. Savi, M.; Bocchi, L.; Bresciani, L.; Falco, A.; Quaini, F.; Mena, P.; Brighenti, F.; Crozier, A.; Stilli, D.; Del Rio, D. Trimethylamine-NOxide (TMAO)-Induced Impairment of Cardiomyocyte Function and the Protective Role of Urolithin B-Glucuronide. Molecules 2018, 23, 549. [CrossRef]

77. Chen, M.I.; Zhu, X.H.; Ran, L.; Lang, H.D.; Yi, L.; Mi, M.T. Trimethylamine-N-Oxide Induces Vascular Inflammation by Activating the NLRP3 Inflammasome Through the SIRT3-SOD2-mtROS Signaling Pathway. J. Am. Heart Assoc. 2017, 6, e006347. [CrossRef] [PubMed]

78. Suzuki, T.; Heaney, L.M.; Bhandari, S.S.; Jones, D.J.; Ng, L.L. Trimethylamine N-oxide and prognosis in acute heart failure. Heart 2016, 102, 841-848. [CrossRef] [PubMed]

79. Janeiro, M.H.; Ramírez, M.J.; Milagro, F.I.; Martínez, J.A.; Solas, M. Implication of Trimethylamine N-Oxide (TMAO) in Disease: Potential Biomarker or New Therapeutic Target. Nutrients 2018, 10, 1398. [CrossRef] [PubMed]

80. Tang, W.H.; Wang, Z.; Fan, Y.; Levison, B.; Hazen, J.E.; Donahue, L.M.; Wu, Y.; Hazen, S.L. Prognostic value of elevated levels of intestinal microbe-generated metabolite trimethylamine-N-oxide in patients with heart failure: Refining the gut hypothesis. J. Am. Coll Cardiol. 2014, 64, 1908-1914. [CrossRef]

81. Tang, W.H.W.; Wang, Z.; Shrestha, K.; Borowski, A.G.; Wu, Y.; Troughton, R.W.; Klein, A.L.; Hazen, S.L. Intestinal microbiotadependent phosphatidylcholine metabolites, diastolic dysfunction, and adverse clinical outcomes in chronic systolic heart failure. J. Card. Fail. 2015, 21, 91-96. [CrossRef] [PubMed] 